\title{
Efficient Institutions and Effective Deterrence: On Timing and Uncertainty of Formal Sanctions
}

\author{
Johannes Buckenmaier ${ }^{1}$ • Eugen Dimant ${ }^{2,3}$ • Ann-Christin Posten ${ }^{4,5}$. \\ Ulrich Schmidt ${ }^{6}$
}

Accepted: 1 July 2021 / Published online: 23 July 2021

(C) The Author(s), under exclusive licence to Springer Science+Business Media, LLC, part of Springer Nature 2021

\begin{abstract}
Economic theory suggests that the deterrence of deviant behavior is driven by a combination of severity and certainty of punishment. This paper presents the first controlled experiment to study a third important factor that has been mainly overlooked: the swiftness of formal sanctions. We consider two dimensions: the timing at which the uncertainty about whether one will be punished is dissolved and the timing at which the punishment is actually imposed, as well as the combination thereof. By varying these dimensions of delay systematically, we find a surprising non-monotonic relation with deterrence: either no delay (immediate resolution and immediate punishment) or maximum delay (both resolution and punishment as much as possible delayed) emerge as most effective at deterring deviant behavior and recidivism. Our results yield implications for the design of institutional policies aimed at mitigating misconduct and reducing recidivism.
\end{abstract}

Keywords Deterrence · Institutions · Punishment · Swiftness · Uncertainty

JEL Classification C91 · D02 · D81 · K42

\section{Introduction}

Governments use substantial resources to keep society safe and punish criminal activities. Annually, mass incarceration costs amount to approximately $\$ 182$ billion in

Eugen Dimant

edimant@sas.upenn.edu

1 University of Zurich, Zurich, Switzerland

2 University of Pennsylvania, Philadelphia, PA, USA

3 CESifo, Munich, Germany

4 University of Cologne, Cologne, Germany

5 University of Limerick, Limerick, Ireland

6 Kiel Institute for the World Economy, Kiel, Germany 
the United States (Wagner \& Rabuy, 2017). The economic tradition to understand deviance and deterrence has its origins in the seminal work by Becker (1968), which stresses the importance of severity and certainty of punishments. ${ }^{1}$ More recently, these concepts have been studied in the domain of uncertainty and ambiguity (see, e.g., DeAngelo \& Charness 2012; for a recent review of economic research, see Chalfin \& McCrary 2017, and for a cross-disciplinary discussion of experimental work, see Engel 2016).

Understanding the deterrence mechanisms of deviant behavior yields important policy implications. However, a particular institutional aspect that is implicitly factored in by Becker's decision framework - the swiftness of punishment - has been under-researched in the economics literature. This concept is often referred to as celerity (see Bailey 1980; Howe \& Brandau 1988; Yu 1994; Nagin \& Pogarsky 2001; Nagin \& Pogarsky 2004). ${ }^{2}$ Historically, this concept has its scholarly roots in the writings of Jeremy Bentham and Cesare Beccaria, and represents a fundamental component in deterrence theory that has been referred to as the "neglected middle child of the deterrence family' (Pratt \& Turanovic, 2018). However, despite theoretical advancements (see, e.g., Nagin 2013), little empirical work has been conducted regarding the celerity of punishment using observational data since there are very few environments where nearly instantaneous punishment or resolution occurs. For this reason, we capitalize on a stylized experimental setting in which we can systematically vary the structure of celerity.

The goal of this paper is to experimentally study the role of timing and uncertainty of formal punishment in deterring deviant behavior - aspects that have received surprisingly little attention in this area of research. Specifically, we are interested in how the timing of formal sanctions (be it conviction or sentencing) and the timing of the resolution of uncertainties surrounding these sanctioning mechanisms affect deterrence. We systematically vary the swiftness of a sanction within a new, stylized, experimental paradigm along the following two dimensions: first, we vary the delay between offense and detection; second, we vary the delay between offense and sanctioning. We also study the combination thereof. Our main objective is to test the behavioral assumption that swiftness matters, which we derived from existing theories (e.g., Loewenstein 1987; Frederick et al. 2002), and to advance our understanding of how to leverage swiftness and the dread of uncertainty as an effective third approach to deter deviance. We argue that swiftness can serve as a useful tool for policy makers to design more efficient and/or potentially also less expensive institutional deterrence mechanisms. Naturally, the concepts of decision-making

\footnotetext{
${ }^{1}$ Recent scholarly contributions have broadened this perspective and emphasized the importance of institutional structures, including staff rotations in the public administration, whistleblower protection, the bite of audits and formal punishment, and use of norm-nudge interventions (Shleifer \& Vishny, 1993; Abbink, 2004; Nikiforakis, 2008; Sutter et al., 2010; Serra, 2011; Balafoutas \& Nikiforakis, 2012; Abbink et al., 2014; Khadjavi, 2014; Engel et al., 2016; Buckenmaier et al., 2018; Bicchieri \& Dimant, 2019; Hajikhameneh \& Rubin, 2019; Dimant \& Gesche, 2020).

${ }^{2}$ Classically, celerity referred exclusively to the temporal delay of a potential sanction following a transgression. We adopt a wider definition of celerity, using it as a catch-all phrase for the timing of the various facets of a deterrence mechanism (Pratt \& Turanovic, 2018). Specifically, we distinguish between the timing of punishment and the timing of the resolution of uncertainty regarding the punishment.
} 
under risk and uncertainty are not limited to the domain of criminal behavior. Most recently, this has been particularly apparent in the context of the COVID-19 pandemic where individual actions (e.g., to wear masks, to social distance, to obtain a vaccination) are guided by the same principles (Viscusi, 2020). The insights of celerity also find broader application beyond criminal behavior, such as finance and consumption (Palacios-Huerta, 1999; Chesson \& Viscusi, 2003). For example, Kreps and Porteus (1978) and Kocher et al. (2014) show that preferences over temporal lotteries also depend on the point in time when the uncertainty is resolved: agents can show a preference for earlier or delayed resolution of uncertainty. Further evidence comes from consumer literature. Anticipatory emotions, compared with outcomebased emotions, are central in prospective consumption situations and the uncertainty associated with anticipatory emotions negatively affects intentions (Bee \& Madrigal, 2013).

Given the high costs involved in increasing punishment's certainty (e.g. costs for an executive body) or punishment's severity (e.g. incarceration costs), we argue that the timing of punishment as well as the timing at which individuals are informed about the consequences, that is, their delay with respect to the transgression in question, can potentially serve as a powerful tool for deterrence. Our findings advocate for changes in institutional structures to increase the effectiveness of deterrence (Bigoni et al., 2015).

More generally, from an aggregate perspective, the speed of justice matters because it facilitates economic development and market efficiency (North, 1991; Djankov et al., 2008; Ponticelli \& Alencar, 2016). Recent empirical results evaluating the impact of legal reform to increase judiciary adjudication in Senegal find an increase in procedural efficiency without any adverse effects on quality (Kondylis $\&$ Stein, 2018). From an individual perspective, existing research in various disciplines indicates that timing affects the association formed in one's mind between the deviant act and the ultimate punishment: without proper swiftness, sanctions risk losing their bite, regardless of how certain or severe they are Chalfin and McCrary (2017) and Pratt and Turanovic (2018) - a fact already prominently argued a long time ago (Watson, 1924).

In reality, the closest we can get to achieving maximal swiftness (celerity) of punishment is by catching deviants in the act and punishing them right away. For example, during the FIFA World Cup 2010 in South Africa, the local government agreed to establish 56 so-called 'World Cup Courts' across the country, assigning 1,500 dedicated personnel including magistrates, prosecutors, and public defenders. This was done to achieve speedy justice, in some cases leading to convictions on the same day. ${ }^{3}$ Recently, the concept of celerity has entered the correctional arena through the project HOPE (Hawaii Opportunity Probation with Enforcement) as a new model for probation. "In 2004, First Circuit Judge Steven Alm launched a pilot program to reduce probation violations by drug offenders and others at high risk of recidivism. This high-intensity supervision program, called HOPE Probation [...], is the first and only of its kind in the nation. Probationers in HOPE Probation receive

\footnotetext{
${ }^{3}$ https://www.theguardian.com/football/2010/jun/20/world-cup-2010-fans-marketing-justice-fifa
} 
swift, predictable, and immediate sanctions - typically resulting in several days in jail - for each detected violation, such as detected drug use or missed appointments with a probation officer" (Alm, 2014). In a first pilot, the project was found to reduce drug use, crime, and incarceration. Simultaneously, it saved the government approximately $\$ 6,000$ per participant per year through reduced incarceration (Hawken \& Kleiman, 2009). ${ }^{4}$

The existing line of research that has acknowledged the relevance of celerity has often resorted to observational studies with mixed approaches and insights. However, as also recognized by this stream of literature, the common absence of reliable observational data and the ability to account for potentially confounding influences (i.e., perceived or actual certainty or severity of punishment) render the study of celerity methodologically challenging (for a critical discussion, see Pratt \& Turanovic 2018). A natural starting point to look for a clean effect is the laboratory environment in which institutional constraints are absent and where we can precisely control the incentives and relevant timings of resolution and punishment (Charness \& DeAngelo, 2018). This is in the spirit of the recent surge of experimental economists studying related topics, such as corruption or tax evasion (e.g., Abbink 2006; Serra 2011) in controlled laboratory environments. This allows us to control the important elements of celerity: anticipation and revelation of information, timing and severity of punishment, and the opportunity to recidivate. Our experimental analysis is based on a novel cheating game where subjects may cheat in periodic instances to increase payoffs. These cheating periods are followed by an investigation such that cheaters will be detected and fined with a given probability. Across different treatments, we systematically vary the timing of both the resolution of uncertainty about whether one will be punished and actually being punished.

We analyze behavior alongside two dimensions: total propensity to cheat and recidivism (cheating conditional on having cheated at least once before). Our results show that delayed resolution of uncertainty has no direct systematic impact on behavior. With respect to the relation between the delay of punishment and deterrence, we observe a u-shaped relationship where deterrence is lowest for delayed punishment combined with no delay in resolution of uncertainty and for delayed resolution combined with no delay of punishment, whereas it is significantly higher for either no delay or a delay combined with delayed resolution of uncertainty. This result is at odds with discounted expected utility and theories of anticipatory utility. From a policy perspective, our results suggest that to improve deterrence mechanisms, punishment should either be swift or delayed and paired with the psychological dread of uncertainty.

Section 2 details our experimental design, procedures, and briefly discusses the existing literature on swiftness and deterrence. Results are presented and discussed in Section 3. We conclude in Section 4.

\footnotetext{
${ }^{4}$ One can, of course, also find settings outside the correctional system (e.g., exam-taking) to test swift versus delayed punishments with variation in timing at which the uncertainty about the punishment could be resolved. Recently, a stream of literature has started examining the role of certainty of punishment in the exam-taking context (Walters \& Morgan, 2019) so that our results are also informative for future research that seeks to incorporate celerity and timing of uncertainty resolution in other domains.
} 


\section{Experimental Design}

Different theories come to different conclusions regarding the implications of the timing of a sanction for deterrence (see Section 3.1 for details). Clearly, this is an important point that has to be taken into consideration for the design of legal institutions. A systematic study of the role of celerity for deterrence poses a serious empirical challenge, because changing the celerity of an enforcement mechanism would most likely impact existing institutional structures on multiple levels. For that reason, isolating the impact of such an intervention is hardly possible in the field. In addition, it is unclear whether an actual or would-be offender is aware of this change or not, making identification almost impossible. Thus, a systematic study of celerity calls for a highly controlled environment that allows for the isolation of the direct effect of institutional changes varying celerity on behavior. Fortunately, the experimental laboratory provides such a controlled environment.

\subsection{The Cheating Game}

We use a simple card game, in which subjects have to guess which card was drawn from a deck of cards. The game is played repeatedly by our subjects for a total of 28 rounds. In certain rounds, subjects are presented with the option to "cheat." Cheating guarantees them the maximum possible payoff for that round. Our goal was to design a simple task where the option to cheat was auxiliary - that is, we wanted the task to be easy to understand - but meaningful, regardless of whether or not the option to cheat was presented. Specifically, we wanted to make sure that cheating was not considered part of the game, but a clear violation of the said game's rules. In the game, a card is randomly drawn from a deck of 32 cards and subjects have to guess which card was drawn. A subject received 10 Experimental Currency Units (ECU) for a correct guess and 4 ECU for an incorrect guess. Given a 1 in 32 chance of being correct, the expected payoff of not cheating is about 4.2 ECU. In some rounds, participants are given the option to cheat. By cheating, participants are allowed to uncover the randomly drawn card before making one's guess, ensuring a correct answer and the maximum payoff of 10 ECU less a possible fine if detected. ${ }^{6}$ Participants were

\footnotetext{
${ }^{5}$ We follow recent experimental literature on deviant behavior highlighting the importance of incorporating framing (e.g., using loaded language) that corresponds to the studied behavior. Most notably, while the literature finds that framing is helpful in making the decision-situation salient, it also finds that it does not conceptually change the decision-environment, e.g. no systematic change in the perceived social norms of a deviant action (Banerjee, 2016) or - at worst - produces no change in deviant behavior in the aggregate when compared to a no framing situation (Dimant et al., 2020). Thus, a priori we have little reason to assume that the use of framing changes the decision environment for our participants, much less so any systematic changes across treatments that could explain our main results. Ultimately, our decision to use framing is backed by Alekseev et al. (2017) who recommend resorting to context-rich language (instead of abstract language) in order to retain tight experimental control.

${ }^{6}$ When subjects decide to cheat, we automatically implement the "right guess" for them. Subjects are informed about this procedure in the instructions. We implement this forced guess to avoid "second thoughts" where a subject cheats, views the drawn card, but chooses a different card.
} 
informed that each instance of cheating will be followed by an "investigation" that would detect cheating with a fixed probability of $25 \%$, the occurrence and outcome of which is only revealed to the participant. ${ }^{7}$

With that, cheating exposes them to the risk of being caught and fined. If caught, the consequences in the form of punishment are twofold. First, the subject has to pay a fine of 10 ECU. Second, the subject is suspended from the game for one round, is not allowed to make any decisions, and cannot earn any ECU. Hence, the total expected fine is about 14.2 ECU including the forfeited expected earnings of 4.2 ECU due to suspension. Consequently, cheating yields an expected payoff of about 6.5 ECU in that round, whereas the expected payoff of not cheating is about 4.2 ECU. Suspended participants are not allowed to play the game for one round and additionally are forced to wait 60 seconds before they are allowed to continue in the next period. We deliberately chose suspension combined with a short waiting period as part of the sanctioning mechanism to increase salience with regard to the timing of sanctions. ${ }^{8}$ While one might argue that a delayed fine in a laboratory context where all "actual" payments are realized at the very end of the experiment decreases the result's robustness, such concerns do not apply to the suspension as it is clearly linked to the particular round a subject is suspended.

In order to make the moral dimension of cheating more salient in our laboratory context, we introduce a third party, represented by a charity, that incurs a monetary damage as a result of cheating. ${ }^{9}$ Specifically, for each experimental session, there is a charity pool of 250 ECU (worth \$25) from which 50 ECU is deducted each time a particular subject decides to cheat. At the end of the experiment, one subject is randomly selected. This subject's behavior is implemented towards the charity and the remainder is donated to "Doctors without Borders." 10 The identity of the subject is not communicated and remains unknown to avoid reputation concerns.

\footnotetext{
${ }^{7}$ To avoid floor and ceiling effects in total cheating behavior, we calibrated the probability of being caught on the basis of pre-tests that were run at the same lab. Such probabilities are common in related experiments studying deviant behavior (see, e.g., Abbink and Serra 2012; Banuri \& Eckel 2012).

${ }^{8}$ Existing research in psychology indicates that delay typically renders the impact of punishment less effective as the connection between the deviant act and the resulting punishment gets lost. Hence, in order to retain effectiveness, any minuscule delay of punishment must come with a clear verbal/cognitive component (for a discussion, see Pratt \& Turanovic 2018). Punishment consists of a monetary and non-monetary component, which is not only more realistic but also follows existing theoretical and experimental literature (e.g., Akerlof 1980; Masclet et al. 2003; Bolton et al. 2020). From a theoretical perspective, criminal behavior involves a trade-off between the utility of a potential gain and the disutility of a sanction in case of detection. Which factors compose the disutility of the sanction is in principle irrelevant for our experimental analysis given our focus on treatment differences of punishment.

${ }^{9}$ Following Eckel and Grossman (1996), Dimant (2019), Bicchieri et al. (2020), and Bolton et al. (2020), we use a charity instead of a participant within each session to increase the salience of the pro- or antisocial decisions; behavior can either benefit or harm a credible institution delivering a public good.

${ }^{10} \mathrm{We}$ chose this charity because it frequently tops the rankings of the most trusted charities globally. That way we could maximize our chances that the implementation of the charity serves the targeted purpose: to evoke a moral dilemma. Importantly, participants were never told - and were not able to observe - the number of other participants taking part in the experiment so that the (perceived) impact of their actions on the charity remained constant across all treatments.
} 


\subsection{Treatments}

We vary the timing in a $2 \times 2$ design along the following two dimensions: the timing of punishment and the timing of the resolution of uncertainty. Resolution of uncertainty regarding whether cheating is detected (and hence whether there are sanctions) is either immediate (IR) or delayed by two periods (DR). Obviously, punishment cannot occur before a sentence is passed and, hence, necessarily occurs after the uncertainty is resolved. Relative to the timing of resolution of uncertainty, punishment is either immediate (no delay or ND) or delayed by 2 rounds (delayed or D). This gives us 4 treatments: $I R-N D, I R-D, D R-N D$, and $D R-D$. To ensure that decisions are not influenced by unresolved risk, each cheating decision was followed by 5 rounds without cheating. 11

All treatments consist of 28 rounds: 4 training rounds followed by 4 blocks of 6 rounds each. In the first 4 rounds participants play the card game without cheating to familiarize themselves with the game and the interface. In the first round of each block, subjects can cheat. In the remaining rounds of a block (rounds 2-6), they play the card game without the option to cheat. Using blocks of 6 rounds allows us to vary both the timing of the resolution of uncertainty, as well as the timing of punishment without an overlap with subsequent cheating decisions.

Table 1 summarizes the four treatments where the timing of punishment is always considered relative to the timing of resolution of uncertainty. In treatment $I R-N D$, subjects experience immediate resolution of uncertainty - instant feedback within the same round about whether cheating was detected. The subjects also experience no delay in punishment. That is, the fine (if due) and the potential suspension are implemented immediately for the next period. In treatment $I R-D$, resolution of uncertainty is again immediate, but now there is a delay in punishment of two periods; when cheating in period $t$, the uncertainty will be resolved immediately, but the potential fine and suspension are executed only in period $t+3$ (as opposed to $t+1$ in $I R$ $N D$ ). We will also refer to $I R-D$ as immediate resolution of uncertainty and delay of punishment. In treatment $D R-N D$, the investigation into cheating does not conclude immediately, but lasts for two additional periods. Only after that is the participant informed about whether his cheating was detected or not. As in $I R-N D$, there is no delay of punishment once uncertainty is resolved. We hence refer to $D R-N D$ as delayed resolution of uncertainty and no delay of punishment. Finally, in treatment $D R-D$, resolution is again delayed, but now punishment is delayed for another two periods after resolution of uncertainty. That is, cheating in period $t$ results in resolution of uncertainty in period $t+2$, followed by the actual punishment (if due) in period $t+5$.

\footnotetext{
${ }^{11}$ For each subject, there were exactly four cheating opportunities, that is, in rounds $5,11,17$, and 23 , subjects were given the opportunity to cheat. Subjects were told that, "occasionally," they will be presented with the option to cheat, but they were not informed about the exact timing and frequency of the occurrence of this option.
} 
Table 1 Overview of timing of resolution of uncertainty and punishment in the different treatments

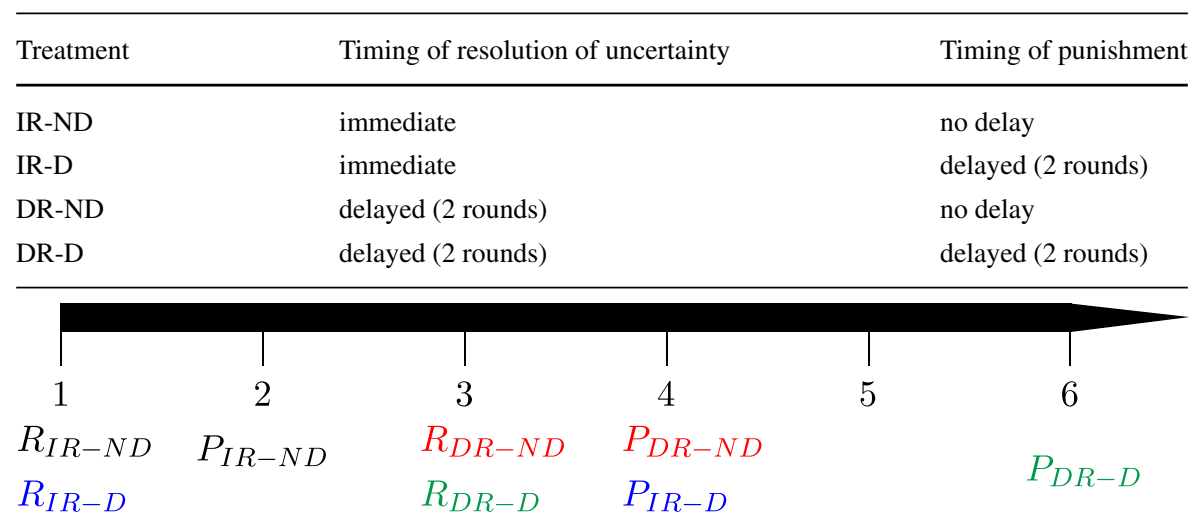

Note: In the timeline, $R$ and $P$ indicate the timing of resolution of uncertainty and timing of punishment for $I R-N D, I R-D, D R-N D$, and $D R-D$, respectively.

\subsection{Experimental Procedures}

We conducted 32 experimental sessions at the Decision Science Lab at Harvard University. Participants were recruited vie e-mail invitation from the laboratory's database which contains students as well as non-students. A total of 296 subjects (46.6\% male) participated in the experiment split between treatments as follows: 66 subjects in $I R-N D, 85$ subjects in $I R-D, 69$ subjects in $D R-N D$ and 76 subjects in $D R-D$. The experiment was programmed and run using z-Tree (Fischbacher, 2007). ${ }^{12}$ Within each session, participants were randomly assigned to a computer booth in which they would participate in the experiment anonymously. The consent forms and instructions for the corresponding treatment were distributed (see instructions in the Online Appendix). Following an informed consent, the participants were given sufficient time to read the instructions carefully. Before the start of the experiment, subjects had to answer a series of comprehension questions in order to check their understanding of the game and its payoff structure. ${ }^{13}$ Subjects then played 28 periods after which they were informed of their total earnings via a detailed summary screen. One subject was randomly drawn to determine the charity pool and all participants were informed about the final amount left in the pool to be donated to "Doctors without Borders." 14 At the end of the experiment, subjects completed a

\footnotetext{
${ }^{12}$ We observed an influx of disproportionately older participants due to a bug in the recruitment software in our first sessions. This was quickly resolved. Participants of 41 years and older represent around $11 \%$ of our data set. Unless noted otherwise, our results are robust with respect to this subgroup.

${ }^{13}$ In all sessions, participants answered comprehension questions on a printout and were first verified by the experimenters before the experiment began.

${ }^{14}$ Prior to the experiment, subjects received a short description of the work of "Doctors Without Borders," which helps to enforce a basic level of common knowledge to increase salience of prosocial behavior. A receipt of the amount donated was made available to all participants via email.
} 
questionnaire containing questions on personal characteristics (demographics, education, income, age), risk-attitudes (SOEP; see Dohmen et al. 2011) ${ }^{15}$, consideration of future consequences (Strathman et al., 1994) and self-control (Tangney et al., 2004).

Sessions lasted approximately 45 minutes excluding the time for payment. A participant's payoff was determined by the sum of his earnings over all 28 rounds. The total payoff in ECU was then converted to dollars at a rate of $10 \mathrm{ECU}=\$ 1$. The average payment was $\$ 14.29$, which included a show-up payment of $\$ 2.50$.

\subsection{The Role of Swiftness in Deterrence}

Standard theories produce conflicting results with respect to the role of timing on deterrence. The classic theoretical approach towards the deterrence of criminal activity (e.g. Becker 1968) is based on the assumption that potential offenders mainly weigh the expected gains against the expected adverse consequences of an offense. This poses an inter-temporal decision problem under uncertainty: the benefits of criminal behavior are usually immediate, whereas any proceeding detection, conviction, and implementation of legal consequences are generally delayed and stochastic. In the standard framework of discounted expected utility, delayed punishment should reduce deterrence due to a discounting effect, whereas the timing of resolution of uncertainty should have no effect on behavior. However, it has been argued that the uncertainty associated with anticipatory emotions negatively affects intentions (Bee \& Madrigal, 2013). Psychological learning theories (Skinner, 1963; Tversky \& Kahneman, 1986; Ehrlich, 1996; Hackenberg, 2009) second the argument that the time between a transgression and the punishment as well as the uncertainty that is associated with the punishment are driving forces for effective behavioral changes. If this is indeed the case, then the classical interpretation of celerity as the time between committing an offense and the actual punishment (e.g. fine or imprisonment) should be complemented by the time the uncertainty is resolved, that is, the time of sentencing.

Starting with the seminal paper of Loewenstein (1987), several theories propose that anticipation of future events is an important determinant of intertemporal utility (see e.g., Wu 1999; Lovallo and Kahneman 2000; Caplin \& Leahy 2001; Dillenberger 2010; Strzalecki 2013; Golman et al. 2019). These models are based on the idea that a non-negligible proportion of the overall consequences from future consumption (be it negative or positive) is already consumed in the form of so-called anticipatory utility before actual consumption takes place. As a consequence, resolution of uncertainty may affect deterrence and the effect of delayed punishment may be reverted, leading to an increase in deterrence (for recent experimental evidence studying preferences for different forms of resolution of uncertainty see e.g. Zimmermann 2014 and Nielsen 2018). While there is growing theoretical literature supporting anticipa-

\footnotetext{
${ }^{15}$ Because the SOEP question is an ordinal scale, we transform the variable into a dummy using the median-split: values $[0,5]$ are coded as ' 0 ' and indicate risk aversion; values $[6,10]$ are coded as ' 1 ' and indicate risk-loving (for a similar approach, see Crosetto \& Filippin 2013, among others). All of our results presented below are robust to alternative specifications such as a mean-split or representing all 11 levels as dummies. These results are available upon request from the authors.
} 
tory utility theory and its implications, little empirical, and especially experimental, work exists. 16

In light of these conflicting predictions, it remains an empirical question to show how the timing of punishment, the timing of resolution of uncertainty, and the interaction thereof affects both deviance and recidivism (learning from experiencing punishment and uncertainty). Our experiment is set out to test these important open questions by systematically varying the structure of the timings. In a last step, we will use our insights to point to future research directions.

\section{Results}

Here, we present our results using parametric and non-parametric comparisons ${ }^{17}$, as well as various regression models to analyze differences in cheating behavior. Please note that not only were the number of cheating opportunities (4) the same in all treatments, but also their position within the block was constant (in the first round of each block). Hence, any difference in behavior can only result from our systematic variation in the timing of punishment and the timing of resolution of uncertainty.

There are a number of factors that might affect the propensity to cheat. First and foremost, risk attitudes might affect the individual propensity to engage in cheating. Hence, it is important to note that we find no differences in risk attitudes across treatment groups (chi-square test of independence, $N=296, \chi^{2}(30)=30.422$, $p=0.296$ ). It is also conceivable that subjects who were detected cheating in a previous round, are more likely to cheat in future rounds to make up for the missed income opportunity. Consequently, differences in punishment frequencies across treatments, especially in early blocks, might introduce a confound. To rule out this possibility, we ran chi-square tests of independence comparing total punishment frequencies and punishment frequencies in the first block across treatments. Both tests show no significant difference across treatments (Overall: $N=1184, \chi^{2}(3)=0.6806, p=0.878$; first block: $N=293, \chi 2(3)=1.6887, p=0.639)$ indicating that the frequency of (randomly) received punishments are comparable across treatments.

First, we look at the mean differences in total cheating across all treatments. Total cheating is defined as the proportion of all individual cheating incidences across all four blocks. We present a graphical illustration in Fig. 1 and regression results in Table 2. We find no significant difference between $I R-D$ and $D R-N D$. However, our results illustrate an interesting inverted $u$-shaped relationship between total cheating and delay of punishment: compared to the $I R-D$ case (immediate resolution, delayed punishment), cheating is significantly lower in both IR-ND (BSM, 53.2\% vs. $38.2 \%$,

\footnotetext{
${ }^{16}$ Two recent exceptions are Falk and Zimmermann (2016), who experimentally tested the implications of anticipatory utility in the context of information preferences and Kogler et al. (2016), who showed that delayed resolution of a tax audit results in higher tax compliance.

${ }^{17}$ We follow Moffatt (2015) and employ the bootstrap two-sample t-test method (hereafter BSM) with 9999 replications to analyze mean differences of average behavior. This has the advantage of retaining the rich cardinal information in the data without making any assumptions about the distribution. Unless noted otherwise, the results are consistent with non-parametric tests.
} 


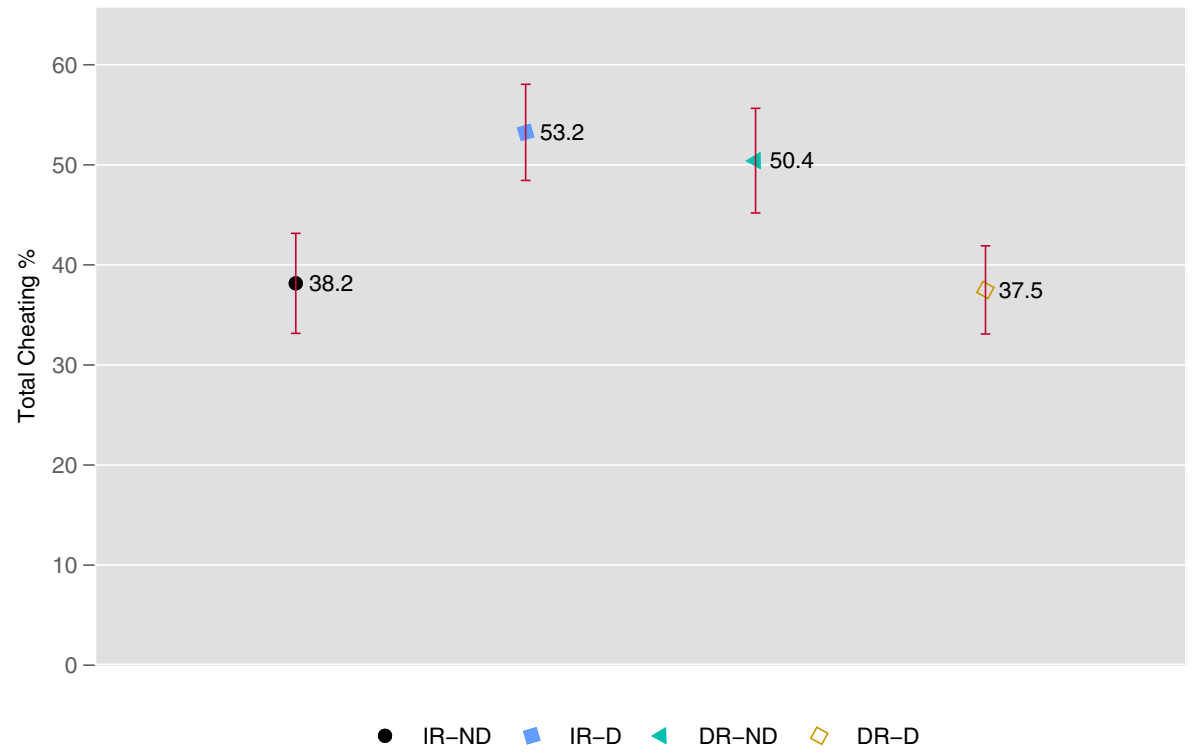

Fig. 1 Total Cheating. Percentage of individual cheating attempts relative to the maximum of possible cheating attempts (four)

$p=0.03)$ and $D R-D(\mathrm{BSM}, 53.2 \%$ vs. $37.5 \%, p=0.02)$. This result alone indicates that the most deterrent form of punishment is either swift or delayed and coupled with a period of unresolved uncertainty. ${ }^{18}$

In order to check for robustness, we capitalize on the panel structure of our data by performing a random effects Logit regression (coefficients represent odds ratios). Our dependent variable in Table 2 is a dummy variable indicating the decision to cheat in each block. For ease of comparison and to improve readability of the results, we use $I R-D$ (immediate resolution, delayed punishment) as our reference category. The regressions include a battery of relevant covariates such as gender, age, block number, number of correct card guesses, and risk preferences. ${ }^{19}$ In model 2, we also control for previous cheating decisions (L.Cheat) and experience with punishment from past cheating (L.Punishment). ${ }^{20}$

\footnotetext{
${ }^{18}$ Compared to $D R-N D$, cheating is marginally lower in both $I R-N D$ (BSM, $50.4 \%$ vs. $38.2 \%, p=0.09$ ) as well as $D R-D$ (BSM, $50.4 \%$ vs. $37.5 \%, p=0.07$ ).

${ }^{19}$ We used the ordinal risk measure of Dohmen et al. (2011) that asked respondents "How willing are you to take risks, in general?" Respondents rate their willingness on an ordinal scale from 0 to 10 . The scale was converted into a dummy variable using a median split. Consequently, all values larger or equal than the median value of 6 were coded as 1 and all values below 6 were coded as 0 .

${ }^{20} \mathrm{We}$ also have measures for awareness of future consequences, self-control, and a participant's previous participation in economic experiments. When we add these as further controls, none are significant and the significance levels of our variables of interest remain unaffected. Hence, we decided to not include them in the reported regression table in the interest of brevity, but results are available upon request.
} 
Table 2 Propensity to Cheat (Random Effects Logit Regression)

\begin{tabular}{|c|c|c|c|c|}
\hline Cheat & $\begin{array}{l}\text { model } 1 \\
\text { All }\end{array}$ & $\begin{array}{l}\text { model } 2 \\
\text { All }\end{array}$ & $\begin{array}{l}\text { model } 3 \\
\text { Female }\end{array}$ & $\begin{array}{l}\text { model } 4 \\
\text { Male }\end{array}$ \\
\hline$I R-N D$ & $\begin{array}{l}0.2985^{* *} \\
(0.1722)\end{array}$ & $\begin{array}{l}0.5529^{* *} \\
(0.1286)\end{array}$ & $\begin{array}{l}0.4518^{* *} \\
(0.1679)\end{array}$ & $\begin{array}{l}0.3851 \\
(0.3391)\end{array}$ \\
\hline$D R-N D$ & $\begin{array}{l}0.9763 \\
(0.5558)\end{array}$ & $\begin{array}{l}0.8078 \\
(0.1817)\end{array}$ & $\begin{array}{l}0.6702 \\
(0.2113)\end{array}$ & $\begin{array}{l}1.1419 \\
(1.0800)\end{array}$ \\
\hline$D R-D$ & $\begin{array}{l}0.3406^{*} \\
(0.1898)\end{array}$ & $\begin{array}{l}0.5563^{* * *} \\
(0.1249)\end{array}$ & $\begin{array}{l}0.4940^{* *} \\
(0.1621)\end{array}$ & $\begin{array}{l}0.3505 \\
(0.3250)\end{array}$ \\
\hline Willing to take risks & $\begin{array}{l}0.8275 \\
(0.3497)\end{array}$ & $\begin{array}{l}0.8434 \\
(0.1446)\end{array}$ & $\begin{array}{l}1.0129 \\
(0.2508)\end{array}$ & $\begin{array}{l}0.3437 \\
(0.2530)\end{array}$ \\
\hline Age & $\begin{array}{l}0.9396^{* * *} \\
(0.0174)\end{array}$ & $\begin{array}{l}0.9811^{* *} \\
(0.0074)\end{array}$ & $\begin{array}{l}0.9841 \\
(0.0132)\end{array}$ & $\begin{array}{l}0.9343^{* *} \\
(0.0272)\end{array}$ \\
\hline Block & $\begin{array}{l}0.8346^{* *} \\
(0.0665)\end{array}$ & $\begin{array}{l}0.9688 \\
(0.0971)\end{array}$ & $\begin{array}{l}0.8997 \\
(0.1307)\end{array}$ & $\begin{array}{l}0.9182 \\
(0.1753)\end{array}$ \\
\hline GuessCorrect & $\begin{array}{l}0.7560 \\
(0.1903)\end{array}$ & $\begin{array}{l}0.9099 \\
(0.0927)\end{array}$ & $\begin{array}{l}1.1024 \\
(0.1709)\end{array}$ & $\begin{array}{l}0.5046^{*} \\
(0.2030)\end{array}$ \\
\hline Male & $\begin{array}{l}6.0081^{* * *} \\
(2.6317)\end{array}$ & $\begin{array}{l}2.0533^{* * *} \\
(0.3536)\end{array}$ & & \\
\hline L.Cheat & & $\begin{array}{l}8.4844^{* * *} \\
(1.4882)\end{array}$ & $\begin{array}{l}12.1630^{* * *} \\
(3.1187)\end{array}$ & $\begin{array}{l}0.4812 \\
(0.3622)\end{array}$ \\
\hline L.Punishment & & $\begin{array}{l}1.6401^{*} \\
(0.4577)\end{array}$ & $\begin{array}{l}1.5647 \\
(0.6123)\end{array}$ & $\begin{array}{l}4.0618^{* *} \\
(2.7446)\end{array}$ \\
\hline Observations & 1184 & 888 & 474 & 414 \\
\hline
\end{tabular}

Note: Odds ratios reported. SEs in parentheses, clustered at the individual level. ${ }^{*} p<0.1$, ${ }^{* *} p<$ 0.05 , ${ }^{* *} p<0.01$. IR-ND, DR-ND, and $D R-D$ are treatment dummies (reference category is $I R-D$ ). Willing to take risks is the median split of our ordinal risk measure (0-10): Values $0-5$ are coded as ' 0 ' indicating risk aversion, whereas values $6-10$ are coded as ' 1 ' indicating risk-loving. Block (1-4) refers to the four blocks (cheating opportunities). GuessCorrect is the number of total correct guesses. Male is a gender dummy. Lagged variables (L.Cheat and L.Punishment) for cheating and punishment are dummies indicating whether an individual cheated or was punished for cheating in the previous round.

Our analysis in Table 2 on the full sample (model 1) suggests that, relative to immediate resolution and delayed punishment $(I R-D)$, both swifter punishment (IR$N D)$ as well as delayed punishment coupled with delayed resolution $(D R-D)$ are significantly less likely to render individual cheating decisions. The introduction of delayed uncertainty resolution, holding the timing of punishment constant (DR-ND), does not significantly affect cheating behavior. A direct comparison of our treatments mirrors this finding, indicating that higher deterrence can be achieved by either implementing swift punishment $(I R-N D)$ or through the combination of delayed uncertainty resolution and delayed punishment $(D R-D)$. Post-estimation tests yield a marginally significant difference between $D R-N D$ and $D R-D(p=0.071)$, and no 
significant difference between the coefficients of $I R-N D$ and $D R-D(p=0.823)$, suggesting that the effectiveness of deterrence is of a similar magnitude in both cases. All of these results corroborate our previously obtained non-parametric comparisons. ${ }^{21}$

The results (model 2) also suggest that cheating behavior increases with both past rounds' cheating behavior and having been caught and punished for cheating. This finding indicates that individuals try to make up for incurred losses by increasing the frequency of cheating and taking larger risks, thus being more risk-seeking in losses. Further, a participant's age is inversely and significantly correlated with one's probability to cheat. ${ }^{22}$ This indicates that potential wealth effects cannot explain cheating behavior. It is worth noting that we observe substantial gender heterogeneity, indicating that males cheat significantly more than females. ${ }^{23}$ To further explore potential heterogeneous effects for males and females, we ran additional regressions with restricted subsamples using only male or female subjects, respectively (model 3 and 4). ${ }^{24}$ All this suggests that swift punishment or delayed punishment in combination with delayed resolution of uncertainty significantly increases the deterrence of deviant behavior. The delay of uncertainty alone remains ineffective.

We conclude that both very efficient (no delay of punishment) and very inefficient (delayed punishment combined with delayed resolution of uncertainty about the status of discovery) punishment institutions are equally effective in deterring deviant behavior. What is more, one could also plausibly assume the presence of learning effects. A large body of existing literature suggests that the learning effects that emerge through experience are shaped by the timing of rewards and punishments. Due to this, they affect subsequent behavior (cf. Camp et al. 1967; Parke \& Deur 1972). This is of particular importance in the punishment context, because such learning effects would directly speak to the occurrence of recidivism among former felons. Following this logic, the experience of uncertainty and punishment following transgressive behavior could lead to differences in subsequent transgressions. We refer to this as recidivism. Recidivism in this context is defined as the propensity to cheat conditional on at least one previous transgression (which can occur at the beginning of any of the first three blocks). The idea behind this measure is to understand whether experiencing the drain of uncertainty of punishment following the first cheating decision will affect the individual's subsequent propensity to cheat. Our results indicate that cheating behavior following the experience of uncertainty and punishment is

\footnotetext{
${ }^{21}$ Applying the conservative measure of one independent observation per participant, post-hoc power calculations indicate that the comparisons to $D R-N D$ achieve statistical power in excess of $87 \%$.

${ }^{22}$ Importantly, the amount of correct guesses in non-cheating rounds, which are the driving force behind potential wealth accumulation in our setting, has no significant predictive power for cheating.

${ }^{23}$ One may argue that this result is partially driven by gender differences in how positive the charity used in this experiment is perceived. We deem this explanation as unlikely based on existing evidence using the same charity that find no gender differences (e.g., Bicchieri et al. 2020; Bolton et al. 2020).

${ }^{24}$ We thank an anonymous reviewer for suggesting these additional analyses. Although male subjects cheat more frequently than females, we find that in these restricted regressions the previously observed treatment effects are only significant for female subjects but not for males. Although gender differences are not the focal point of our investigation, our results are consistent with Croson and Gneezy (2009) who found that females are generally more sensitive to the contextual frame.
} 
congruent to our previous findings on unconditional cheating behavior. We present a graphical illustration in Fig. 2.

In order to shed light on this mechanism, we employ the same estimation approach as before, but now restrict our sample to observations where participants have cheated at least once before. Our dependent variable of interest continues to be the propensity to cheat in any given period. Through these regressions, reported in Table 3, we look to analyze the propensity to recidivate and continue to cheat.

Our results for recidivism are consistent with our previous findings, suggesting that the recidivism of individuals is lowest when punishment is either immediate or late and paired with uncertainty. The delay of uncertainty alone is ineffective. We again find an inverted u-shaped relationship; when combining delayed punishment with uncertainty of resolution, recidivism rates return to levels similar to those found when immediate punishment is paired with immediate uncertainty resolution (IR$N D)$. In support of this, post estimation tests show that the drop in recidivism rates in $D R-D$ is marginally significant compared to cheating in $D R-N D(p=0.077)$. In contrast to total cheating behavior, we do not observe gender heterogeneity for recidivism, except in $D R-N D$, where males are significantly more likely to recidivate (interaction not shown in the table). Age continues to be inversely related to cheating propensity. We observe a particularly interesting finding for the lagged cheating and lagged punishment variables. The results suggest that following one's previous decision to cheat, subsequent cheating decisions become less likely, unless previ-

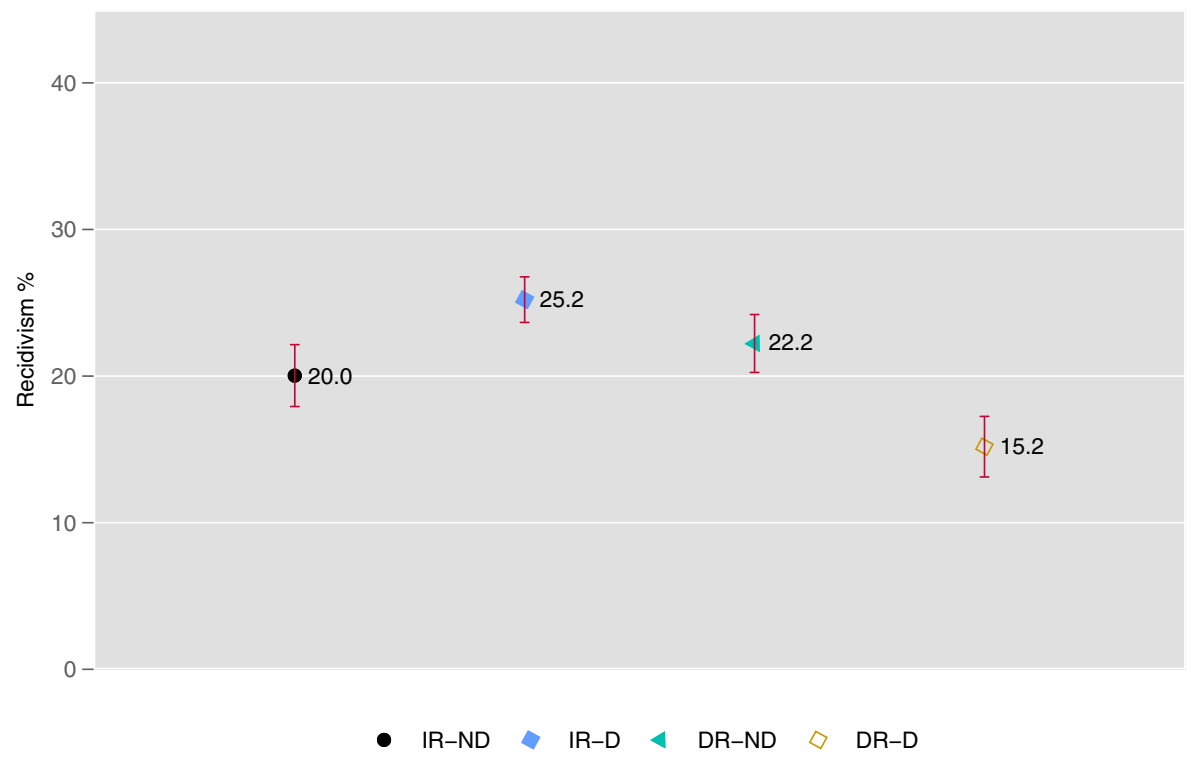

Fig. 2 Recidivism. Percentage of individual cheating attempts relative to the maximum of possible cheating attempts following their first cheating decision 
Table 3 Propensity to recidivate (Random Effects Logit Regression)

\begin{tabular}{|c|c|c|c|}
\hline Cheat & model 1 & model 2 & model 3 \\
\hline \multirow[t]{2}{*}{$I R-N D$} & $0.3008^{* *}$ & $0.2045^{* *}$ & $0.2437^{*}$ \\
\hline & $(0.1719)$ & $(0.1605)$ & $(0.2030)$ \\
\hline \multirow[t]{2}{*}{$D R-N D$} & 0.6005 & 0.5095 & 0.5164 \\
\hline & $(0.3311)$ & $(0.3794)$ & $(0.4094)$ \\
\hline \multirow[t]{2}{*}{$D R-D$} & $0.2192^{* * *}$ & $0.1229^{* * *}$ & $0.1018^{* * *}$ \\
\hline & $(0.1235)$ & $(0.0978)$ & $(0.0877)$ \\
\hline \multirow[t]{2}{*}{ Willing To Take Risks } & 0.6751 & 0.6312 & 0.6084 \\
\hline & $(0.2797)$ & $(0.3553)$ & $(0.3568)$ \\
\hline \multirow[t]{2}{*}{ Age } & $0.9608^{* *}$ & $0.9475^{* *}$ & $0.9441^{* *}$ \\
\hline & $(0.0183)$ & $(0.0252)$ & $(0.0263)$ \\
\hline \multirow[t]{2}{*}{ Block } & 0.8588 & $0.6229^{* *}$ & $0.6002^{* *}$ \\
\hline & $(0.1377)$ & $(0.1436)$ & $(0.1443)$ \\
\hline \multirow[t]{2}{*}{ GuessCorrect } & $0.5165^{* * *}$ & $0.4269^{* *}$ & $0.4161^{* *}$ \\
\hline & $(0.1293)$ & $(0.1489)$ & $(0.1510)$ \\
\hline \multirow[t]{2}{*}{ Male } & $2.1710^{*}$ & $2.7598^{*}$ & $2.8255^{*}$ \\
\hline & $(0.9201)$ & (1.6057) & (1.7118) \\
\hline \multirow[t]{2}{*}{ L.Cheat } & & $0.2031^{* * *}$ & $0.1781^{* * *}$ \\
\hline & & $(0.1228)$ & $(0.1107)$ \\
\hline \multirow[t]{2}{*}{ L.Punishment } & & $3.5587^{* *}$ & 5.0887 \\
\hline & & $(1.7547)$ & (5.8578) \\
\hline \multirow[t]{2}{*}{ L.Punishment $\times I R N D$} & & & 0.2687 \\
\hline & & & $(0.3842)$ \\
\hline \multirow[t]{2}{*}{ L.Punishment $\times$ DRND } & & & 0.7242 \\
\hline & & & $(1.0636)$ \\
\hline \multirow[t]{2}{*}{ L.Punishment $\times$ DRD } & & & 1.5303 \\
\hline & & & $(2.1741)$ \\
\hline Observations & 493 & 493 & 493 \\
\hline
\end{tabular}

Note: Odds ratios reported. SEs in parentheses, clustered at the individual level. ${ }^{*} p<0.1{ }^{* *} p<$ 0.05 , ${ }^{* * *} p<0.01$. IR-ND, $D R-N D$, and $D R-D$ are treatment dummies (reference category is $I R-D$ ). Willing to take risks is the median split of our ordinal risk measure (0-10): Values $0-5$ are coded as ' 0 ' indicating risk aversion, whereas values $6-10$ are coded as ' 1 ' indicating risk-loving. Block (1-4) refers to the four blocks (cheating opportunities). GuessCorrect is the number of total correct guesses. Male is a gender dummy. Lagged variables (L.Cheat and L.Punishment) for cheating and punishment are dummies indicating whether an individual cheated or was punished for cheating in the previous round.

ous cheating was accompanied with punishment. In the latter case, participants are substantially more likely to recidivate, which suggests recidivism is driven by one's desire to make up for previous losses. To further investigate whether previous punishment has a differential treatment effect, we ran an additional regression that interacts lagged punishment with the treatment dummies. We find all interactions to be non- 
significant. Post-estimation tests show that the overall effects identified above remain unchanged. ${ }^{25}$

In summary, we can conclude that the same institutional settings that are capable of reducing recidivism are also the ones deterring deviant behavior in the first place. Our results demonstrate that swift or delayed punishment combined with an extensive dread of uncertainty regarding one's detection reduces future criminal behavior.

\subsection{Discussion}

In this section, we discuss our results in light of existing theories of intertemporal decision making. Specifically, we seek to illustrate how deterrence should be affected by our two main treatment variables, the delay of punishment and the timing of resolution of uncertainty, given a certain theoretical framework. We consider two prominent theories that seem particularly important for our setting, discounted expected utility theory (DEU) and utility from anticipated emotions (UAE). For brevity, we will focus on the intuition behind derived implications and delegate the formal derivation to the Appendix.

Intuitively, most theories of temporal discounting suggest that future costs or benefits receive a lower weight than immediate ones; this weight decreases as one moves further into the future (Frederick et al., 2002). First, we consider a standard DEU model with discount factor $0<\delta<1$, and for simplicity, restrict attention to a single block of six periods involving one cheating opportunity only. Note that in this model, the timing of the resolution of uncertainty does not affect utility. Furthermore, note that only the utility generated from cheating differs across treatments and that this utility is larger the more the punishment is delayed. Hence, if a potential offender discounts delayed legal consequences, then deterrence decreases as the delay extends. As a consequence, higher celerity (less delay) would increase the efficiency of legal sanctions, which is the classical hypothesis in criminology literature (Nagin \& Pogarsky, 2004; Paternoster, 2010). Thus, according to DEU, the efficacy of deterrence decreases as the delay of punishment increases, independent of the timing of resolution of uncertainty. In particular, the point in time where the uncertainty is resolved has no effect on deterrence.

Our results provide only limited support for this implication. When resolution of uncertainty is immediate, we find the expected effect of an additional delay of punishment. However, if resolution of uncertainty is delayed this effect is reversed.

We remark that empirically the above implication of DEU has to be taken with some caution. Gains are usually discounted with a positive rate, making earlier gains more attractive than delayed ones. However, fines are losses, and the evidence for discounting of losses is rather mixed. While studies consistently show that losses are discounted less than gains, it is unclear whether the discount rate for losses is positive, equal to zero, or even negative (Thaler, 1981; Loewenstein, 1987; MacKeigan et al., 1993).

\footnotetext{
${ }^{25}$ Linear combination test: IR-ND + L.Punishment $\times$ IR-ND $(\beta=0.0655, p=0.070)$.
} 
Second, we turn to theories of anticipatory utility, which incorporate anticipatory feelings such as excitement, fear or dread into classical expected utility theory. DEU fails to take such considerations into account. These theories suggest that one might want to bring forward an unpleasant event to shorten the period of dread (or delay a positive event to enjoy the excitement for a longer period of time). The idea is that future events influence current utility. More precisely, negative future events cause more negative utility today the further away the event is (at least up to a certain point). If this effect outweighs the discounting effect described above, then a further delay increases deterrence due to the negative utility from anticipation. Consequently, in UAE, deterrence increases in the delay of punishment if the effect of anticipation is sufficiently high, for a fixed timing of resolution of uncertainty.

Anticipated emotions in Loewenstein's model refer to future consumption under certainty. Caplin and Leahy (2001) extend this model by allowing for uncertainty and point toward the importance of anticipatory feelings prior to the resolution of uncertainty. Anticipatory emotions, such as anxiety, are often predicated on an uncertain future and thus, are mainly relevant prior to the resolution of uncertainty. As a consequence, the point in time at which uncertainty is resolved matters. For example, Kreps and Porteus (1978) and Kocher et al. (2014) show that preferences over temporal lotteries also depend on the point in time when the uncertainty is resolved. That is, agents can show a preference for earlier or delayed resolution of uncertainty. Caplin and Leahy (2001) argue that anxiety experienced one period before the resolution of uncertainty should depend on both the detection probability and the severity of the punishment. Typically, this anxiety, if large enough, leads to a preference for early resolution of uncertainty for negative outcomes. That is, if the effect of anxiety experienced just before the resolution of uncertainty is large enough, a decision-maker discounting future events will prefer to resolve this uncertainty as late as possible to minimize the impact of anxiety. Thus, under UAE, delayed resolution of uncertainty increases deterrence if anxiety prior to the resolution of uncertainty is large enough and the timing of punishment is held fixed.

Given that the effect of anticipation and anxiety are large enough, the combined effect of delayed resolution and delayed punishment can be grasped by comparing, for example, $D R-N D$ to $I R-N D$. Taken together the combination of both effects predicted by UAE imply an increase in deterrence when the delays of both punishment and resolution are increased. To summarize, UAE implies a positive effect of delayed punishment on cheating, in contrast to DEU. Delayed resolution of uncertainty may matter under UAE, potentially further increasing deterrence.

Finally, we want to briefly remark that, recently, Baucells and Bellezza (2017) proposed a new theory of inter-temporal decision making. They extend the existing models of anticipatory utility by a reference point which adjusts. It does so during the anticipation phase by altering a utility of recall in the periods succeeding the consumption and changing the magnitude effect in discounting. In this theory it is possible that the utility maximizing timing of an unpleasant event is somewhere in the middle of the time horizon, i.e. fines in earlier or later periods hurt more and should, therefore, lead to higher deterrence. While our experiment was not designed to test this theory, it is the only theory which is compatible with the findings of our experiment. 


\section{Conclusion}

We investigate along two dimensions how timing can impact the effectiveness of sanctions. We use a controlled laboratory experiment designed to study the effect of delayed punishment and delayed resolution of uncertainty on deterrence. Our experimental findings show that the timing of resolution of uncertainty has no effect on deterrence. For the delay of punishment, we observe the following inverted u-shaped relationship: deterrence is highest for no delay or delayed punishment combined with delayed resolution, whereas it is lowest when there is delayed resolution but no delay in punishment or when there is delayed punishment but no delay in resolution of uncertainty. The observed inverted u-shape is at odds with both discounted expected utility theory and anticipatory utility theory. According to the first theory, deterrence should decrease monotonically with the delay of punishment. According to the second, there should also be a monotonic relation between deterrence and delay, which would be the inverse of that in the previous case if the effect of anticipation is sufficiently high.

It is important to note that the effects of treatments on the total cheating behavior can be obtained by two different, possibly simultaneous operating processes. First, the variations in the experimental treatments could have affected the participants' anticipatory reasoning about how a possible punishment would impact them. If the impact is anticipated to be severe, this could lead to delayed or no cheating. Second, learning processes may have affected cheaters who (at least once) underwent the respective treatments differently by experiencing the (non)waiting for a resolution of uncertainty and the potential execution of an immediate or delayed punishment. This may have influenced their likelihood to cheat again in the future. Inspecting the results for recidivism (i.e. future cheating upon having cheated before) shows that they closely mirror the results of the total cheating behavior. Even if some experience for the treatments to become effective would be needed, basic learning theories (e.g. Azrin 1956; Banks \& Vogel-Sprott 1965) are at odds with the inverted u-shaped relation between deterrence and delay of punishment also observed for recidivism.

Arguably, the highly effective deterrence of deviant behavior in $D R-D$ could be interpreted in one of the following two ways: firstly, only a delay of punishment, and not the existence of uncertainty resolution, is responsible for the decrease in cheating; secondly, it is the combination of both the delay in punishment and the existence of uncertainty that imposes additional dread and, thus, the interaction of both is driving the strength of deterrence. Our results and theoretical foundation suggest that it is most likely the former. We consider this as a promising venue for future research.

Our findings yield important insights for optimally designing sanctioning schemes in legal systems. Existing deterrence literature has almost exclusively focused on the role of severity and certainty of legal consequences in deterring proscribed actions. Our study shows that celerity, the timing of sanctions through sentencing, may also be a crucial component of an effective legal system. Our results imply that if deterrence is to be maximized, then the punishment should either follow the criminal act quickly or be delayed and combined with uncertainty. As immediate punishment may be relatively costly, an optimally delayed punishment along with a certain 
degree of uncertainty could be the most efficient solution to reduce both deviance and recidivism.

Our study provides a first step into analyzing the effects of deterrence in a sanctioning system. In order to draw conclusions for an optimal policy in the real world, future research needs to tackle several limitations of our study. In particular, it seems necessary to study celerity when the delay of punishment extends to the real payout of subjects. While the concept of celerity has already been backed theoretically in the scholarly literature for an extended period of time, only recently has the concept of celerity entered the correctional arena through the project HOPE (Hawaii Opportunity Probation with Enforcement) as a new model for sanctions and probation (Hawken \& Kleiman, 2009; Kilmer et al., 2013; Alm, 2014; Nicosia et al., 2016). More research should follow and consider additional aspects such as the role of optimal delay, which can be very sensitive to the type of punishment (e.g. the optimal delay may be rather different for monetary fines than for imprisonment). With this in mind, we are confident that our study highlights the role of celerity in designing optimal sanctioning systems and points to fruitful avenues for future research.

Supplementary Information The online version contains supplementary material available at doi:10.1007/s11166-021-09352-x.

\section{Appendix: Theoretical analysis}

In this appendix, we provide further details regarding the derivation of the behavioral implications outlined in Section 3.1. We present the formal derivation of those implications for discounted expected utility theory (DEU) and utility from anticipated emotions (UAE). In the standard discounted expected utility (DEU) model, optimal decisions do not depend on the timing of resolution of uncertainty. In the DEU model, a delay of punishment should decrease deterrence. The utility of not cheating $(N C)$ is identical in all treatments and is given by

$$
\operatorname{DEU}(N C)=\frac{31}{32} 4+\frac{1}{32} 10
$$

where we assume for convenience a linear utility function. ${ }^{26}$ We restrict attention to a single block consisting of 6 periods, where cheating was possible in the first round of that block. Furthermore, we only consider the utility generated from the decision about cheating in the first period of such a block in all our analyses. The remaining utility components within a block are identical across treatments. In all treatments, detected cheaters are fined 10 ECU plus one round of suspension for a total expected fine of $F=10+\operatorname{DEU}(N C)$, but the time at which the punishment occurs varies across treatments. In the baseline treatment, detected cheaters are punished directly

\footnotetext{
${ }^{26}$ While risk aversion modeled by a concave utility function certainly influences the decision between cheating and not cheating, it does not imply differences between treatments.
} 
in the next period. For a discount factor $\delta<1$, the utility of cheating $(C)$ amounts to

$$
\operatorname{DEU}(C, \mathrm{IR}-\mathrm{ND})=10-\frac{1}{4} \delta F
$$

as cheating is not possible in the next period. Compared to the baseline treatment, punishment is delayed by two further periods in $I R-D$. The same is true for $D R-N D$. As the timing of resolution of uncertainty is immaterial under DEU, we get

$$
\operatorname{DEU}(C, \mathrm{IR}-\mathrm{D})=\operatorname{DEU}(C, \mathrm{DR}-\mathrm{ND})=10-\frac{1}{4} \delta^{3} F .
$$

Finally, we have

$$
\operatorname{DEU}(C, \mathrm{DR}-\mathrm{D})=10-\frac{1}{4} \delta^{5} F .
$$

as punishment is delayed by a total of four periods in $D R-D$.

Since $\operatorname{DEU}(C, \mathrm{IR}-\mathrm{ND})<\operatorname{DEU}(C, \mathrm{IR}-\mathrm{D})=\operatorname{DEU}(C, \mathrm{DR}-\mathrm{ND})<$ $\operatorname{DEU}(C, \mathrm{DR}-\mathrm{D})$ where the utility of not cheating is independent of the treatments, we get the prediction:

Proposition 1 Under DEU, increasing the delay of punishment decreases deterrence for a fixed timing of resolution of uncertainty.

As a consequence, DEU predicts more violations in $I R-D$ compared to $I R-N D$ and more violations in $D R-D$ compared to $D R-N D$. Since the timing of resolution of uncertainty does not affect behavior, following DEU violations in Treatments $I R-D$ and $D R-N D$ are identical.

Proposition 2 Under DEU, the timing of resolution of uncertainty does not affect behavior, implying that violations in Treatments IR-D and DR-ND are identical.

Proposition 3 Since under DEU the timing of resolution of uncertainty does not change deterrence and increasing the delay of punishment decreases deterrence, we will have more violations in DR-ND than in IR-ND and more violations in DR-D than in IR-D.

Following Loewenstein (1987), negative future outcomes can cause immediate disutility through negative anticipatory emotions such as fear, dread, or anxiety. DEU fails to take this into consideration. Suppose you were cheating in the baseline treatment. Then, you dread in the first period that you will be fined in the next one, i.e. you dread a loss of $F=10+\operatorname{DEU}(N C)$. For a discount rate $\gamma$, which measures the degree to which current utility is influenced by anticipated emotions from consumption in the next period, the utility of cheating is given by

$$
\operatorname{UAE}(C, \mathrm{IR}-\mathrm{ND})=10-\frac{1}{4}(\delta+\gamma) F
$$

where UAE denotes utility with anticipated emotions. We now consider $I R-D$ where there is a delay of punishment by two periods. Note that the utility from anticipation is discounted with discount factor $\delta$. While the discounting effect in Eq. 3 increases 
utility compared to $I R-N D$, anticipation leads to decreasing utility as dread is now experienced in more than one period. More specifically, we get

$$
\mathrm{UAE}(C, \mathrm{IR}-\mathrm{D})=10-\frac{1}{4} \delta^{3} F-\frac{1}{4}\left(\gamma^{3}+\delta \gamma^{2}+\delta^{2} \gamma\right) F
$$

Comparing Eqs. 5 and 6, it may well be that the utility of cheating is lower in $I R-D$ than in $I R-N D$ if $\gamma$ is sufficiently high. Since the utility of not cheating is identical across treatments, we get the opposite of Proposition 1.

Proposition 4 If the effect of anticipation is sufficiently high, delaying punishment increases deterrence leading to less violations in IR-D compared to IR-ND and in $D R-D$ compared to $D R-N D$.

Anticipated emotions in the model of Loewenstein (1987) refers to future consumption under certainty. In Treatments $D R-N D$ and $D R-D$, resolution of uncertainty is delayed which may alter anticipatory emotions. While in $I R-D$ a detected cheater may feel dread in periods 1-3 due to anticipating the punishment in period 4 , in $D R$ $N D$ a cheater may experience the anxiety of being detected in the later investigation. Following Caplin and Leahy (2001), the anxiety experienced one period before resolution should depend on the probability of being detected and the size of the fine. As all these parameters are identical in Treatments $D R-N D$ and $D R-D$, we simply use the term $A$ to denote the anxiety of a cheater one period before resolution. We now introduce a third discount rate $\alpha$, such that anxiety experienced $t$ periods before resolution is given by $\alpha^{t} A$. This yields the following utility of cheating in $D R-N D$ :

$$
\mathrm{UAE}(C, \mathrm{DR}-\mathrm{ND})=10-\frac{1}{4} \delta^{3} F-\left(\alpha+\delta \alpha^{2}\right) A-\frac{1}{4} \delta^{2} \gamma F
$$

Typically, it is observed that people prefer early resolution of uncertainty for negative outcomes. In our model this is the case if

$$
\left(\alpha^{2}+\delta \alpha\right) A>\frac{1}{4}\left(\gamma^{3}+\delta \gamma^{2}\right) F
$$

and leads to the following hypothesis:

Proposition 5 Delayed resolution of uncertainty increases deterrence leading to less violations in DR-ND compared to IR-D.

If the resolution of uncertainty should be delayed to increase deterrence, punishment has to be delayed as it cannot precede the resolution of uncertainty. The combined effect of delayed resolution and delayed punishment can be grasped by comparing $D R-N D$ to $I R-N D$. If both delaying punishment according to Proposition 4 and delaying resolution according to Proposition 5 increases deterrence, our UAE implies the following: 
Proposition 6 If delaying punishment increases deterrence due to dread and delayed resolution also increases deterrence due to anxiety, then the combined effect of delaying punishment and resolution results in less cheating and, therefore, less violations in DR-ND compared to IR-ND.

Let us finally consider the utility of cheating in $D R-D$. Here we get

$$
\mathrm{UAE}(C, \mathrm{DR}-\mathrm{D})=10-\frac{1}{4} \delta^{5} F-\frac{1}{4}\left(\gamma^{3}+\delta \gamma^{2}+\delta^{2} \gamma^{3}+\delta^{3} \gamma^{2}+\delta^{4} \gamma\right) F
$$

The cheater experiences anxiety prior to the resolution of uncertainty as in $D R-N D$, but there is also an extended period where he may experience dread due to delayed punishment. The second component is similar to the dread experienced in $I R-D$, additionally discounted as the experience starts two periods later. Assuming condition (8) holds, a comparison of Eqs. 9 and 6 reveals that the utility of cheating in $D R-D$ will be smaller than that of cheating in $I R-D$ under the conditions of Proposition 4. This leads to the following result:

Proposition 7 If condition (8) holds and the effect of anticipation is sufficiently high ( $\gamma$ is large enough), then delayed resolution combined with delaying punishment results in less cheating leading to fewer violations in $D R-D$ compared to $I R-D$ and fewer violations in DR-D compared to IR-ND.

Acknowledgements We would like to thank Dan Ariely, Gary Bolton, Catherine Eckel, Christoph Engel, Simon Gächter, Kyle Hyndman, and David Rand for helpful remarks and input. We are also indebted to Gary Charness for comprehensive input on an earlier version of our experimental design. Comments at workshops and conferences, most notably the CESifo Venice Summer Institute, the 'Norms, Actions and Games' Workshop at the Institute for Advanced Study, the Morality, Incentives and Unethical Behavior Conference at UCSD, the Max Planck Institute for Economics, the London School of Economics (Behavioural Science Hub), Yale University (Human Cooperation Laboratory), the University of Pennsylvania (Solomon Laboratories of Experimental Psychology), and the Institute for the World Economy are greatly appreciated. Generous financial support through the Edmond J. Safra Center for Ethics at Harvard University and the Heinz Sauermann Award by the German Society for Experimental Economic Research $(\mathrm{GfeW})$ is acknowledged. An expedited IRB approval through Harvard University was obtained under IRB15-0625.

\section{References}

Abbink, K. (2004). Staff rotation as an Anti-Corruption policy: an experimental study. European Journal of Political Economy, 20(4), 887-906.

Abbink, K. (2006). 14 Laboratory Experiments on Corruption. In S. Rose-Ackermann (Ed.) International Handbook on the Economics of Corruption (pp. 418-438). Cheltenham: Edward Elgar.

Abbink, K., Dasgupta, U., Gangadharan, L., \& Jain, T. (2014). Letting the briber go free: an experiment on mitigating harassment bribes. Journal of Public Economics, 111, 17-28.

Abbink, K., \& Serra, D. (2012). Anticorruption policies: lessons from the lab. In New advances in experimental research on corruption. Emerald Group Publishing Limited.

Akerlof, G. A. (1980). A theory of social custom, of which unemployment may be one consequence. The Quarterly Journal of Economics, 94(4), 749-775.

Alekseev, A., Charness, G., \& Gneezy, U. (2017). Experimental methods: When and why contextual instructions are important. Journal of Economic Behavior \& Organization, 134, 48-59. 
Alm, S. S. (2014). HOPE Probation and the new drug court: a powerful combination. Minnesota Law Review, 99, 1665.

Azrin, N. H. (1956). Some effects of two intermittent schedules of immediate and Non-Immediate punishment. Journal of Psychology, 42(1), 3-21.

Bailey, W. C. (1980). Deterrence and the celerity of the death penalty: a neglected question in deterrence research. Social Forces, 58(4), 1308-1333.

Balafoutas, L., \& Nikiforakis, N. (2012). Norm enforcement in the city: a natural field experiment. European Economic Review, 56(8), 1773-1785.

Banerjee, R. (2016). On the interpretation of bribery in a laboratory corruption game: moral frames and social norms. Experimental Economics, 19(1), 240-267.

Banks, R. K., \& Vogel-Sprott, M. (1965). Effect of delayed punishment on an immediately rewarded response in humans. Journal of Experimental Psychology, 70(4), 357.

Banuri, S., \& Eckel, C. (2012). Experiments in culture and corruption: A review. The World Bank.

Baucells, M., \& Bellezza, S. (2017). Temporal profiles of instant utility during anticipation, event, and recall. Management Science, 63(3), 729-748.

Becker, G. S. (1968). Crime and punishment: an economic approach. Journal of Political Economy, 76(2), 169-217.

Bee, C. C., \& Madrigal, R. (2013). Consumer uncertainty: the influence of anticipatory emotions on ambivalence, attitudes, and intentions. Journal of Consumer Behaviour, 12(5), 370-381.

Bicchieri, C., \& Dimant, E. (2019). Nudging with Care: The Risks and Benefits of Social Information. Public Choice, forthcoming.

Bicchieri, C., Dimant, E., Gaechter, S., \& Nosenzo, D. (2020). Social proximity and the erosion of norm compliance. Working Paper Available at SSRN: https://ssrn.com/abstract=3355028 or https://doi.org/10.2139/ssrn.3355028.

Bigoni, M., Fridolfsson, S.-O., Le Coq, C., \& Spagnolo, G. (2015). Trust, leniency, and deterrence. Journal of Law, Economics, and Organization, 31(4), 663-689.

Bolton, G., Dimant, E., \& Schmidt, U. (2020). Observability and Social Image: On the Robustness and Fragility of Reciprocity. Working Paper Available at SSRN: https://ssrn.com/abstract=3294375 or https://doi.org/10.2139/ssrn.3294375.

Buckenmaier, J., Dimant, E., \& Mittone, L (2018). Experimental Evidence on Tax Evasion, Corruption and and Incentives to Blow the Whistle. Journal of Economic Behavior and Organization, forthcoming.

Camp, D. S., Raymond, G. A., \& Church, R. M. (1967). Temporal relationship between response and punishment. Journal of Experimental Psychology, 74(1), 114.

Caplin, A., \& Leahy, J. (2001). Psychological expected utility theory and anticipatory feelings. Quarterly Journal of Economics, 116(1), 55-79.

Chalfin, A., \& McCrary, J. (2017). Criminal deterrence: a review of the literature. Journal of Economic Literature, 55(1), 5-48.

Charness, G., \& DeAngelo, G. (2018). Law and economics in the laboratory. In Research Handbook on Behavioral Law and Economics. Edward Elgar Publishing.

Chesson, H. W., \& Viscusi, W. K. (2003). Commonalities in time and ambiguity aversion for long-term risks. Theory and Decision, 54(1), 57-71.

Crosetto, P., \& Filippin, A. (2013). The "bomb" risk elicitation task. Journal of Risk and Uncertainty, $47(1), 31-65$.

Croson, R., \& Gneezy, U. (2009). Gender differences in preferences. Journal of Economic Literature, 47(2), 448-474.

DeAngelo, G., \& Charness, G. (2012). Deterrence, expected cost, uncertainty and voting: experimental evidence. Journal of Risk and Uncertainty, 44(1), 73-100.

Dillenberger, D. (2010). Preferences for One-Shot resolution of uncertainty and Allais-Type behavior. Econometrica, 78(6), 1973-2004.

Dimant, E. (2019). Contagion of Pro-And Anti-Social behavior among peers and the role of social proximity. Journal of Economic Psychology, 73, 66-88.

Dimant, E., \& Gesche, T. (2020). Nudging enforcers: How norm perceptions and motives for lying shape sanctions. Working Paper.

Dimant, E., van Kleef, G. A., \& Shalvi, S. (2020). Requiem for a nudge: Framing effects in nudging honesty. Journal of Economic Behavior \& Organization, 172, 247-266.

Djankov, S., Hart, O., McLiesh, C., \& Shleifer, A. (2008). Debt enforcement around the world. Journal of Political Economy, 116(6), 1105-1149. 
Dohmen, T., Falk, A., Huffman, D., Sunde, U., Schupp, J., \& Wagner, G.G. (2011). Individual risk attitudes: Measurement, determinants, and behavioral consequences. Journal of the European Economic Association, 9(3), 522-550.

Eckel, C. C., \& Grossman, P. J. (1996). Altruism in anonymous dictator games. Games and Economic Behavior, 16(2), 181-191.

Ehrlich, I. (1996). Crime, punishment, and the market for offenses. Journal of Economic Perspectives, $10(1), 43-67$.

Engel, C. (2016). Experimental criminal law. A Survey of Contributions from Law, Economics and Criminology. Mimeo.

Engel, C., Goerg, S. J., \& Yu, G. (2016). Symmetric vs. asymmetric punishment regimes for collusive bribery. American Law and Economics Review, 18(2), 506-556.

Falk, A., \& Zimmermann, F. (2016). Beliefs and Utility: Experimental Evidence on Preferences for Information. Mimeo.

Fischbacher, U. (2007). z-Tree: Zurich toolbox for ready-made economic experiments. Experimental Economics, 10(2), 171-178.

Frederick, S., Loewenstein, G., \& O’Donoghue, T. (2002). Time discounting and time preference: a critical review. Journal of Economic Literature, 40(2), 351-401.

Golman, R., Loewenstein, G. F., Molnar, A., \& Saccardo, S. (2019). The Demand for, and Avoidance of, Information. Working Paper Available at SSRN: https://ssrn.com/abstract=2149362 or https://doi.org/10.2139/ssrn.2149362.

Hackenberg, T. D. (2009). Token reinforcement: a review and analysis. Journal of the Experimental Analysis of Behavior, 91(2), 257-286.

Hajikhameneh, A., \& Rubin, J. (2019). Exchange in the absence of legal enforcement: reputation and multilateral punishment under uncertainty. Journal of Law, Economics, and Organization, 35(1), 192237.

Hawken, A., \& Kleiman, M. (2009). Managing drug involved probationers with swift and certain sanctions: evaluating hawaii's HOPE: executive summary. Washington, DC: National Criminal Justice Reference Services.

Howe, E. S., \& Brandau, C. J. (1988). Additive effects of certainty, severity, and celerity of punishment on judgments of crime deterrence scale value. Journal of Applied Social Psychology, 18(9), 796-812.

Khadjavi, M. (2014). On the interaction of deterrence and emotions. Journal of Law Economics, and Organization, 31(2), 287-319.

Kilmer, B., Nicosia, N., Heaton, P., \& Midgette, G. (2013). Efficacy of frequent monitoring with swift, certain, and modest sanctions for violations: insights from South Dakota's 24/7 sobriety project. American Journal of Public Health, 103(1), e37-e43.

Kocher, M. G., Krawczyk, M., \& van Winden, F. (2014). 'Let Me Dream on!' Anticipatory Emotions and Preference for Timing in Lotteries. Journal of Economic Behavior and Organization, 98, 29-40.

Kogler, C., Mittone, L., \& Kirchler, E. (2016). Delayed feedback on tax audits affects compliance and fairness perceptions. Journal of Economic Behavior and Organization, 124, 81-87.

Kondylis, F., \& Stein, M. (2018). The speed of justice. World Bank Policy Research Working Paper No. 8372. Available at SSRN: https://ssrn.com/abstract=3147322.

Kreps, D. M., \& Porteus, E. L. (1978). Temporal resolution of uncertainty and dynamic choice theory. Econometrica, 46(1), 185-200.

Loewenstein, G. (1987). Anticipation and the valuation of delayed consumption. Economic Journal, 97(387), 666-684.

Lovallo, D., \& Kahneman, D. (2000). Living with uncertainty: attractiveness and resolution timing. Journal of Behavioral Decision Making, 13(2), 179.

MacKeigan, L. D., Larson, L. N., Draugalis, J. R., Bootman, J. L., \& Burns, L. R. (1993). Time preference for health gains versus health losses. PharmacoEconomics, 3(5), 374-386.

Masclet, D., Noussair, C., Tucker, S., \& Villeval, M.-C. (2003). Monetary and nonmonetary punishment in the voluntary contributions mechanism. American Economic Review, 93(1), 366-380.

Moffatt, P. G. (2015). Experimetrics: Econometrics for Experimental Economics. Palgrave Macmillan.

Nagin, D. S. (2013). Deterrence in the twenty-first century. Crime and Justice, 42(1), 199-263.

Nagin, D. S., \& Pogarsky, G. (2001). Integrating celerity, impulsivity, and extralegal sanction threats into a model of general deterrence: theory and evidence. Criminology, 39(4), 865-892.

Nagin, D. S., \& Pogarsky, G. (2004). Time and punishment: delayed consequences and criminal behavior. Journal of Quantitative Criminology, 20(4), 295-317. 
Nicosia, N., Kilmer, B., \& Heaton, P. (2016). Can a Criminal Justice Alcohol Abstention Programme with Swift, Certain, and Modest Sanctions (24/7 Sobriety) Reduce Population Mortality? A Retrospective Observational Study. The Lancet Psychiatry, 3(3), 226-232.

Nielsen, K. (2018). Preferences for the Resolution of Uncertainty and the Timing of Information. Working Paper.

Nikiforakis, N. (2008). Punishment and counter-punishment in public good games: Can we really govern ourselves? Journal of Public Economics, 92(1-2), 91-112.

North, D. C. (1991). Institutions. Journal of Economic Perspectives, 5(1), 97-112.

Palacios-Huerta, I. (1999). The aversion to the sequential resolution of uncertainty. Journal of Risk and Uncertainty, 18(3), 249-269.

Parke, R. D., \& Deur, J. L. (1972). Schedule of punishment and inhibition of aggression in children. Developmental Psychology, 7(3), 266.

Paternoster, R. (2010). How Much Do We Really Know About Criminal Deterrence?. Journal of Criminal Law and Criminology, pp. 765-824.

Ponticelli, J., \& Alencar, L. S. (2016). Court enforcement, bank loans, and firm investment: evidence from a bankruptcy reform in brazil. Quarterly Journal of Economics, 131(3), 1365-1413.

Pratt, T. C., \& Turanovic, J. J. (2018). Celerity and deterrence. In Deterrence, Choice, and Crime, (Vol. 23 pp. 197-220). Routledge.

Serra, D. (2011). Combining Top-Down and Bottom-Up accountability: evidence from a bribery experimen. Journal of Law Economics, and Organization, 28(3), 569-587.

Shleifer, A., \& Vishny, R. W. (1993). Corruption. Quarterly Journal of Economics, 108(3), 599-617.

Skinner, B. F. (1963). Operant behavior. American Psychologist, 18(8), 503.

Strathman, A., Gleicher, F., Boninger, D. S., \& Edwards, C.S. (1994). The consideration of future consequences: weighing immediate and distant outcomes of behavior. Journal of Personality and Social Psychology, 66(4), 742.

Strzalecki, T. (2013). Temporal resolution of uncertainty and recursive models of ambiguity aversion. Econometrica, 81(3), 1039-1074.

Sutter, M., Haigner, S., \& Kocher, M. G. (2010). Choosing the carrot or the stick? endogenous institutional choice in social dilemma situations. The Review of Economic Studies, 77(4), 1540-1566.

Tangney, J. P., Baumeister, R. F., \& Boone, A. L. (2004). High Self-Control predicts good adjustment, less pathology, better grades, and interpersonal success. Journal of Personality, 72(2), 271-324.

Thaler, R. (1981). Some empirical evidence on dynamic inconsistency. Economics Letters, 8(3), 201-207.

Tversky, A., \& Kahneman, D. (1986). Rational choice and the framing of decisions. Journal of Business, 59(4), S251-S278.

Viscusi, W. K. (2020). Pricing the global health risks of the covid-19 pandemic. Journal of Risk and Uncertainty, 61(2), 101-128.

Wagner, P., \& Rabuy, B. (2017). Following the Money of Mass Incarceration. Prison Policy Initiative.

Walters, G. D., \& Morgan, R. D. (2019). Certainty of punishment and criminal thinking: Do the rational and non-rational parameters of a student's decision to cheat on an exam interact? Journal of Criminal Justice Education, 30(2), 276-295.

Watson, J. B. (1924). Behaviorism. Norton.

Wu, G. (1999). Anxiety and decision making with delayed resolution of uncertainty. Theory and Decision, 46(2), 159-199.

Yu, J. (1994). Punishment celerity and severity: testing a specific deterrence model on drunk driving recidivism. Journal of Criminal Justice, 22(4), 355-366.

Zimmermann, F. (2014). Clumped or Piecewise? Evidence on Preferences for Information. Management Science, 61(4), 740-753.

Publisher's note Springer Nature remains neutral with regard to jurisdictional claims in published maps and institutional affiliations. 